\title{
A cultura visual e o olhar antropológico
}

RICARDO CAMPOS

\section{Resumo}

Com este artigo procuramos desencadear uma reflexão em torno da relação possível entre a Antropologia e o campo interdisciplinar da Cultura Visual. Se é verdade que, apesar de residual, a presença da esfera visual faz parte, desde sempre, da história da Antropologia, também parece evidente que esta relação entre a imagem e a disciplina antropológica assenta, sobretudo, no uso das metodologias visuais em trabalho de terreno e na produção de documentos visuais (filmes etnográficos, fotoensaios, etc.). Ora o campo da Cultura Visual, forjado no cruzamento de interesses e patrimónios disciplinares múltiplos, sugere que a dimensão visual na cultura humana é altamente complexa, abrindo caminho a abordagens informadas por distintas perspectivas e quadros teórico-metodológicos. Neste contexto, entendemos que a Antropologia, com a sua prática metodológica privilegiada - a etnografia -, poderá contribuir para adensar a trama em torno dos debates sobre a visualidade humana, sobre a produção, partilha e consumo de bens visuais.

Palavras-Chave:

Cultura visual, antropologia visual, etnografia, métodos visuais 


\title{
Visual Culture and the anthropological insight
}

\author{
RICARDO CAMPOS
}

\begin{abstract}
With this paper we intend to reflect on the possibilities of a closer relationship between the discipline of Anthropology and the interdisciplinary field of Visual Culture. If it is true that, although residual, the presence of the visual sphere has always been a crucial feature in the history of anthropology, it also seems clear that the connection between image and this scientific discipline has been essentially constructed on the basis of a practical use of the visual technologies (photography, cinema, video). Thus the importance granted to the visual methodologies in fieldwork and the consequent production of visual documents (ethnographic films, photoessays, etc.). Currently the field of Visual Culture, forged at the crossroads of multiple disciplinary interests and assets, suggests that the visual dimension in human culture is highly complex, making way to new approaches informed by different perspectives and theoretical and methodological frameworks. In this context, we believe that anthropology, with its prime methodological practice - ethnography - has something to say. It

\section{can contribute to thicken the debates around human} visuality, regarding essentially the social processes of visual production, sharing and consumption.
\end{abstract}

Keywords: Visual culture, visual anthropology, ethnography, visual methods 


\section{Introdução}

Neste artigo proponho contribuir para um debate que, embora não sendo inaugural, parece algo arredado das discussões públicas situadas no campo disciplinar da Antropologia e, também, da Cultura Visual - ou seja, a relação possível entre a Antropologia (as suas ferramentas epistemológicas e teóricas) e o campo de estudo da Cultura Visual. Desde logo, identifica-se aqui uma disparidade evidente que remete para a história e o património de ambos os campos de conhecimento. A antropologia, com uma longa tradição centenária, assenta numa série de pressupostos epistemológicos consolidados ao longo do tempo, enquanto a cultura visual, é um campo de investigação recente, tendencialmente multidisciplinar e em busca de uma identidade académica sólida. Tal clivagem não nos deve atemorizar ou julgar por inconsequente qualquer espécie de comunicação e intercâmbio entre ambas. Antes pelo contrário. Sugiro que ambas têm muito a ganhar com um estreitar dos laços. A antropologia, por um lado, porque desde a crise da representação etnográfica despoletada na década de 8o, vagueia em busca de caminhos alternativos que expressem novas formas de investigar e comunicar em ciência. A subdisciplina da antropologia visual tem, aqui, especial relevância, na medida em que sempre procurou linguagens inovadoras, buscando criar as condições para uma proximidade entre os domínios da estética e da epistemologia em ciências sociais. Já em anteriores ocasiões (CAMPOS, 2008, 2010), procurei defender os mútuos benefícios deste convívio e, na minha prática de investigação, tenho estado particularmente atento às possíveis correspondências entre a Cultura Visual e algumas correntes da Antropologia Visual'. Tenho, por isso, insistido na ideia de que, para se fazer antropologia 
visual na actualidade, é impossível não reflectir sobre uma das questões fundadoras da Cultura Visual enquanto programa de investigação: a natureza construída do olhar e das formas de expressão e comunicação visual.

Para quem se situa no domínio da arte e da estética, os benefícios do olhar antropológico são imensos. Estas vantagens estão, desde logo, evidentes na própria consagração do termo cultura visual. A institucionalização deste conceito marca, como afirma Pinney (2006), uma viragem da história de arte em direcção à antropologia. Esta vertente está, desde logo, evidente na presença do termo cultura neste binómio, que é, como sabemos, o conceito estruturante do empreendimento epistemológico da Antropologia. Esta marca antropológica está, então, presente na maior ênfase colocada no exame dos processos sociais, em detrimento de uma análise focada nos artefactos visuais (PINNEY, 2006). Isto implica perspectivar a imagem e a visão a partir das sociedades humanas, detalhando os quadros sociais, culturais e históricos que sustentam as produções imagéticas mas, igualmente, a "ética, política, estética e epistemologia, do ver e do ser visto" (MITCHELL, 2002, p.87). Como tal, torna-se fundamental pensar as pontes e movimentos recíprocos entre estes dois horizontes disciplinares.

\section{O que entendemos por Cultura Visual?}

Para começar devemos colocar, de imediato a seguinte questão: o que é, afinal, a Cultura Visual? Pergunta disparatada dirão alguns. Todavia, num contexto em que os debates em torno da identidade e do caminho a trilhar por esta área de estudo estão, ainda, especialmente vivos, julgo que convém assinalar as diversas formas de conceber esta noção e, especialmente, como esta poderá ser abordada na perspectiva das ciências sociais (particularmente da Antropologia e Sociologia). Para mais, parece não existir consenso relativamente ao significado e conteúdo do termo, na medida em que este ora aponta para uma área disciplinar ou temática, ora é operacionalizado enquanto conceito, ora endereça para um modo de adjectivação de uma particular condição civilizacional (WALKER e CHAPLIN, 1997; MITCHELL, 2002). Esta indefinição gera, inclusive, alguma confusão na medida em que as variadas acepções se sobrepõem e, por vezes, tornam complicada a tarefa de destrinçar os limites semânticos desta noção. Em meu entender as diferentes concepções apontam para uma tríade que passarei a descrever. 
Uma primeira definição está associada à identificação de um horizonte de investigação com fronteiras relativamente elásticas. Por cultura visual, muitos entendem uma área de investigação relativamente recente, forjada a partir de múltiplos contributos disciplinares e agendas académicas. Assim, mais que uma disciplina institucionalizada, esta parece ser uma grande área de estudo de tendência transdisciplinar, acolhendo investigadores provenientes de ramos científicos, artísticos e humanísticos que buscam, grosso modo, algo comum: entender a imagem, o olhar e a visualidade enquanto construções humanas, social e historicamente situadas (WALKER e CHAPLIN, 1997). Daí que esta área abarque artistas, mas igualmente pesquisadores de história de arte, de arquitectura, de cinema e fotografia, de psicologia, de sociologia e antropologia, etc. Nalguns contextos esta área de investigação é denominada de Estudos Visuais o que se revela, em meu entender, mais correcto e semanticamente próximo do verdadeiro sentido epistemológico daquilo que é visado. Os estudos visuais, à semelhança dos estudos culturais, onde normalmente são incorporados, correspondem a um conjunto de abordagens multi e interdisciplinares que, em comum, possuem unicamente o seu objecto: a imagem, a visão e a visualidade. Apesar de não existir consenso relativamente a esta matéria, cuja polémica é acentuada pela diversidade de filiações científico-académicas dos investigadores e pela ausência de fronteiras institucionais, Mitchell (2002) opta por definir sucintamente estudos visuais como a área de estudo da cultura visual. Poster (2002), por seu lado, opta por circunscrever estudos visuais a uma disciplina dedicada ao estudo dos media. Walker e Chaplin, resumem esta questão nos seguintes termos, assim clarificando o alvo deste campo de estudo:

aqueles que estudam a cultura visual não estão primordialmente preocupados com como as pessoas vêem o mundo, mas como as pessoas vêem imagens fixas e em movimento e uma série de artefactos que foram criados, em parte ou na íntegra, para serem olhados (WALKER e CHAPLIN, 1994, p. 22)

Numa segunda versão, a noção de Cultura Visual remete para um horizonte particular da produção cultural humana, nomeadamente para o universo composto por linguagens e bens de natureza visual. Deste modo, a cultura visual de uma comunidade ou povo, seria constituída não apenas pelas suas criações pictóricas e gráficas mas, igualmente, pelas gramá- 
ticas visuais e suas formas de comunicação, bem como, pelas relações sociais, culturais e simbólicas que se estabelecem no âmbito da fabricação e partilha dos bens visuais. Os mesmos Walker e Chaplin (1994, p. 1-2) definem, então, cultura visual como o conjunto de "artefactos materiais, edifícios e imagens, mais os media artísticos e performances, produzidos pelo trabalho ou imaginação humana, servindo fins estéticos, simbólicos, ritualísticos ou político-ideológicos e/ou funções práticas, e que invocam o sentido da visão de forma significativa”.

Por último, a Cultura Visual é, recorrentemente, utilizada como epíteto para adjectivar a nossa condição contemporânea, tida por muitos como profundamente imersa no reino da imagem. Logo a nossa cultura ocidental, industrializada, fortemente globalizada e consumista, marcada por um convívio próximo com os media audiovisuais e com a tecnologia, poderia ser descrita como uma cultura visual. Como justificação para este estado de coisas, muitos autores apontam o papel central dos mass-media audiovisuais, da publicidade e do consumo, que promovem uma crescente estilização e estetização da vida quotidiana. Todos estes elementos encontram na imagem e na comunicação visual formas privilegiadas de contar narrativas e atribuir sentido simbólico ao mundo que nos rodeia. Mirzoeff fala, mesmo, de visualização da existência, afirmando que "a vida moderna desenrola-se no ecrã (...) a experiência humana é actualmente mais visual e visualizada do que alguma vez antes" (MIRZOEFF, 1999, p.1). Outros autores referem que esta é uma era ocularcêntrica (JENKS, 1995), onde a visão ganha estatuto privilegiado, em detrimento dos outros órgãos sensoriais² (CLASSEN, 1997; SYNNOTT, 1992). É um facto, igualmente, que diferentes invenções tecnológicas têm, principalmente desde o século XIX, reforçado grandemente esta capacidade para visualizarmos o mundo e comunicarmos através da imagem ${ }^{3}$. Prefiro, nesse caso, utilizar o qualificativo visualista, quando nos referimos a um modelo cultural fortemente inoculado pela imagem e pela dimensão visual.

Gostaria, por isso, de fazer esta destrinça de modo a clarificar conceitos e a facilitar o entendimento dos argumentos que proponho. Estudos visuais (ou área disciplinar de cultura visual) como território de investigação; Cultura Visual como sub-universo particular no interior de um universo cultural, constituindo-se como um objecto de estudo passível de exploração; e por último, Cultura Visualista como qualificativo.

Interessa-me, aqui, abordar essencialmente a segunda acepção, que remete para a uma esfera particular da cultura, 
construída e partilhada por um colectivo de pessoas (sociedade, grupo, comunidade, etc.). A minha perspectiva relativamente à cultura visual é, consequentemente, a seguinte. Entendo-a como um sistema em que os modos de olhar e representar visualmente o que nos rodeia são, histórica e culturalmente, modelados. Deste modo, não abrange unicamente os processos de produção de artefactos visuais e de comunicação visual mas, igualmente, a forma particular como as relações estabelecidas no âmbito do visível se processam. Quem olha o quê e de que modo, são indagações centrais para entender a cultura visual de um determinado período histórico ou recorte social. Estas são questões tanto mais cruciais quanto se sabe que as assimetrias estabelecidas no campo da visibilidade reproduzem posições diferenciadas no campo social (BRIGHENTI, 2007), definindo quem pode ver, que tecnologias dispõem para o fazer e como se constroem representações visuais sobre o quê ou quem é observado. De igual forma, tais discrepâncias são reveladoras sobre quem é mirado e porquê. O poder, material e simbólico, é, tantas vezes, expresso através das relações que se estabelecem no campo do visível. A nossa cultura tipificou, aliás, certas entidades que incorporam, claramente, o poder (e a perversão) presentes no olhar absoluto e unidireccional. O "big brother" ou o "voyeur" são claros exemplos dessas assimetrias. São igualmente, modelos prototípicos servindo na nossa cultura para qualificar uma certa actuação no campo da visibilidade, revelando, ainda, até que ponto todos somos, em diferentes momentos da nossa vida e em certas circunstâncias, big brothers ou voyeurs. Estas são questões que se podem colocar em campos tão distintos de criação imagética como os das artes visuais (pintura, fotografia, cinema, etc.), dos media e da cultura de massas (televisão, publicidade, quadrinhos, etc.) ou, simplesmente, da vida quotidiana (fotografias e vídeos de família, etc.).

Deste modo, a cultura visual pode ser tida como um sistema composto por um conjunto de universos e sub-universos, com os seus agentes, objectos e processos particulares de produção, difusão e recepção de bens visuais. É um sistema não estático, mas em constante renovação, fruto da velocidade de transformação dos agentes, dos processos tecnológicos e das forças de poder que determinam relações de cooperação e conflito. É igualmente, uma cosmovisão, uma forma particular de percepcionar e retratar a realidade, aliada não apenas a modos de ver, mas a modelos sensoriais e modos de retratar a realidade que apelam a diferentes linguagens, capacidades cognitivas e modelos sensoriais ${ }^{4}$. 
Podemos, mesmo, falar de uma cultura visual dominante aceitando, por hipótese, a existência de diversas micro ou subculturas visuais em conexão com desiguais composições sociais, propostas estéticas ou ideológicas, interesses e intenções, que apresentem formas alternativas, não necessariamente antagonistas, de olhar e representar visualmente o mundo. A visualidade está presente na ideologia, na economia, na religião, na mente individual e colectiva, dá corpo a ideias, pensamentos, desejos e necessidades, sendo por estes alimentada.

Em suma, a cultura visual, pode ser entendida, em primeiro lugar, como um repositório visual associado a contextos colectivos particulares, onde determinadas linguagens e signos visuais são elaborados e trocados; em segundo lugar, como um modo de apreender e descodificar visualmente a realidade, tendo em consideração a natureza cultural e psico-social da percepção e cognição; e, em terceiro lugar, como um sistema composto por um aparato tecnológico, político, simbólico e económico, enquadrado num horizonte sociocultural e histórico mais amplo com o qual convive, que ajuda a moldar, tal como é por este configurado.

\section{A antropologia e o seu olhar}

É sabido que a antropologia é uma disciplina particularmente vocacionada para observar tendo, ao longo da sua história, desenvolvido uma determinada forma de olhar para aquilo que nos rodeia. Esta foi, desde as suas origens, uma disciplina incumbida de estudar o Outro distante, o mundo cultural exótico, contribuindo para a produção de significados acerca da nossa identidade e da alteridade. Esta disciplina foi validada enquanto ciência que olha e retrata o Outro. Adquiriu legitimidade política, ideológica e científica nesta matéria, contribuindo fortemente para a fabricação da cartografia étnico-cultural do nosso planeta. Não podemos esquecer a importância que o poder político desempenha na sua afirmação, nomeadamente no período colonial, atribuindo à antropologia autoridade para explorar e inventariar os diferentes redutos étnico-culturais que povoavam os territórios coloniais. Identificar e catalogar eram pressupostos de um regime que procurava conhecer para melhor dominar. O que parece estar na origem desta premente necessidade de olhar e retratar visualmente o mundo encontra-se num simples facto: a diferença. A diferença expressa-se no mundo material dos corpos, das vestimentas, 
da arquitectura e dos objectos. A diferença ao projectar-se, de forma crua, no domínio do visível, clama por um processo de captação visual. Daí a importância do olhar e da necessidade do seu apuramento. A antropologia fundou um modo de olhar que transcende paradigmas epistemológicos e permanece, ainda hoje, como principal veículo de reconhecimento da alteridade nas suas manifestações culturais, simbólicas e materiais, servindo à edificação de uma série de imagens e imaginários sobre as comunidades que nos são distantes geográfica e simbolicamente.

Não é de estranhar, por isso, que as tecnologias de registo em imagem tenham sido, inicialmente, bem acolhidas pelos antropólogos. Algumas das grandes expedições etnográficas realizadas em finais do século XIX e inícios do século XX iam munidas de aparelhos de captação de imagens (e sons). A primeira utilização do filme no trabalho de terreno etnográfico, empregue como documento visual com objectivos científicos surge com a expedição britânica liderada por Alfred Haddon em 1898, ao estreito de Torres. O êxito da expedição de Haddon 5 influenciou projectos posteriores, como o de Baldwin Spencer e Frank Gillen ${ }^{6}$. Referências basilares da antropologia científica, Franz Boas e Malinowski também empregaram a câmara fotográfica nos seus empreendimentos etnográficos.

O uso destes aparelhos era, inicialmente, justificado pela crença na objectividade e neutralidade das provas visuais produzidas através de instrumentos que serviam fielmente os pressupostos e deveres de uma ciência positivista. A proximidade com os princípios epistemológicos das ciências naturais e exactas, que caracterizava a antropologia, compelia a uma completa inventariação, catalogação, descrição e comparação dos objectos. Os métodos de trabalho de campo inspiravam-se, igualmente, no poder da ilustração para a construção de taxinomias e para o reconhecimento visual do mundo, tal como era defendido na botânica, na zoologia ou geologia. A documentação de natureza visual cumpria neste caso uma função inestimável, pois para além de permitir registar com fidelidade uma realidade objectiva, possibilitava a catalogação e comparação (PIAULT, 1995a; PINNEY, 1996; EDWARDS, 1996). Todavia, apesar dos primeiros anos promissores, a imagem foi lentamente perdendo peso nas ciências sociais por uma razão, aparentemente paradoxal. A imagem que era, nos seus primórdios tida por auxiliar de investigação, dada a sua natureza documental e a fidelidade à 
realidade retratada é, gradualmente, tida por pouco rigorosa dada a sua polissemia e superficialidade. É verdade, também, que uma alteração de paradigma, reforça a componente cultural da antropologia em detrimento da componente física, tornando-a menos atenta à superfície material do mundo (e à sua catalogação) e mais interessada em compreender e conceptualizar intelectualmente a realidade cultural (SAMAIN, 1998; BANKS e MORPHY, 1997).

Se é um facto que a antropologia desde cedo conviveu com as imagens, coloca-se a seguinte questão: o que é, então, a antropologia visual? Ora só faz sentido compreender a existência desta subdisciplina precisamente pelo rumo histórico que tomou a antropologia e que determinou a lenta marginalização da imagem. Não por acaso, diversos autores insistem em falar de uma disciplina de palavras (MEAD, 1995 [1975]). Na verdade, esta periferização de uma prática etnográfica com imagens conduziu à criação de um reduto disciplinar, com uma identidade e programa epistemológico próprios. Daí a institucionalização, a partir da década de 7o, da Antropologia Visual. Esta, apesar das diferentes tendências no seu seio, prevê, grosso modo, o uso das tecnologias de registo visual na pesquisa etnográfica. Actualmente, a prática de investigação com imagens (e sons), nomeadamente com recurso a aparelhos digitais, parece estar a tornar-se uma actividade banal. Daí o maior interesse pelo uso da imagem que se reconhece na gradual multiplicação dos centros de investigação especializados e na oferta de formação nesta área. Os estudantes e jovens investigadores em ciências sociais parecem fortemente motivados para o uso destas tecnologias inscritas em programas de pesquisa ${ }^{7}$.

A história da Antropologia Visual é, assim, uma história de fazer imagens e de analisar imagens. Esta é uma duplicidade, mesmo uma ambiguidade, que acompanha o percurso desta subdisciplina. O antropólogo visual, através de diferentes tecnologias de registo de imagem (fotografia, vídeo, filme) retrata certas realidades e, como tal, é ele próprio criador de imagens (pensa-se a si mesmo como autor de discursos, de narrativas visuais). É, porém, um estudioso de imagens, das suas e das dos outros. É um investigador atento aos filmes e fotografias que produziu, mas também, especialmente interessado na análise das imagens e sistemas visuais de uma certa comunidade. Neste sentido partilha muitos dos interesses e desígnios daqueles que se situam no âmbito dos Estudos Visuais. 


\section{Que contributos pode a Antropologia trazer para o estudo da Cultura Visual?}

Após esta breve digressão em torno daquilo que entendo por Estudos Visuais e por Cultura Visual estaremos, neste momento, em condições de detalhar qual a relação que estas podem estabelecer com a Antropologia. Retornando ao que afirmei anteriormente, e fazendo uma súmula simplificada dos meus argumentos, podemos afirmar que os Estudos Visuais podem ser entendidos como área que estuda a cultura visual. Neste sentido partilho a perspectiva defendida por Mitchell (2002). Ou seja, os estudos visuais, incluiriam todos os empreendimentos de pesquisa de natureza diversa (artística, sociológica, psicológica, antropológica, etc.) que visem estudar a cultura visual numa das múltiplas vertentes que esta pode assumir.

Noutras ocasiões argumentei que fazia sentido a Antropologia Visual resgatar uma série de questões do património teórico dos estudos visuais (CAMPOS, 2008). Em primeiro lugar, porque falta à antropologia visual uma mais profunda teorização em torno da visualidade humana, dos processos e das tecnologias do olhar. A antropologia visual tem estado demasiado centrada nos processos de registo e comunicação (áudio)visual sendo, por isso, claramente dominada pela corrente do filme etnográfico (RUBY, 2005; RIBEIRO, 2004). Ora, os estudos visuais apresentam uma abordagem multidisciplinar que é extremamente interessante e vantajosa e que vem ao encontro, em primeiro lugar, daquilo que muitos autores reclamam como as novas vias da antropologia visual (MORPHY e BANKS, 1997; MACDOUGALL, 1997; SAMAIN, 1998), mais atentas aos fenómenos da visualidade humana e ao estudo dos sistemas visuais; e, em segundo lugar, da própria natureza híbrida do programa desta subdisciplina, situada entre a arte e a ciência, entre o domínio da epistemologia e da estética. Daí que, para compreender mais profundamente o olhar e os processos através dos quais se produzem representações (áudio)visuais sobre o mundo, faça sentido uma mais próxima comunicação entre estas duas áreas.

Foquemo-nos, agora, na área dos Estudos Visuais. Foi anteriormente dito que, no cerne das preocupações daqueles que se debruçam sobre a cultura visual, se encontram questões de natureza antropológica, ou seja, a forma como o olhar, a criação pictórica e o desfrute visuais são, social, cultural e historicamente, forjados. Resta-nos, pois, procu- 
rar entender como o património teórico e epistemológico da Antropologia pode trazer novas modalidades de exploração da cultura visual que solidifiquem, por um lado, o próprio conceito e, por outro lado, reforcem e enriqueçam a área de investigação dos estudos visuais. Sugerimos que a antropologia pode ser útil a diferentes níveis.

O primeiro contributo, talvez o mais óbvio, remete-nos para o processo metodológico característico da Antropologia, a etnografia. Por etnografia entendemos não apenas um método, mas um paradigma epistemológico, uma forma singular de aceder à realidade social e de descrever essa realidade; um modo particular de entender os agentes sociais e a actuação do investigador no meio circundante; e, em última análise, uma forma peculiar de pensar a própria ciência (e as relações que esta estabelece com outras áreas de conhecimento e de discurso sobre a realidade).

A etnografia é, então, um processo de imersão que emprega uma panóplia de instrumentos de indagação e recolha de informação que, como referem Atkinson e Hammersley (1988, p. 15), constituem "refinamentos ou desenvolvimentos dos que são usados na vida quotidiana", na medida em que envolvem um conjunto de interacções sociais ${ }^{8}$. Estabelecer relações sociais e envolver-se no quotidiano, no espaço e no tempo das pessoas é, então, a via epistemológica de base para um trabalho etnográfico. Tal pressupõe a presença no terreno e alguma disponibilidade física e temporal para as pessoas, para as ouvir e acompanhar9. Daí o enfoque que geralmente é concedido à questão da experiência etnográfica, como forma singular de estar, de sentir uma determinada situação social. Deste modo, o método etnográfico permite partilhar o quotidiano, os processos e as experiências subjectivas dos produtores e consumidores dos bens visuais. Este método faculta um olhar ao investigador que parte dos próprios protagonistas culturais, concedendo voz àqueles que são os sujeitos directamente envolvidos nos processos criativos. Há, inclusive, diversos estudos etnográficos que apontam nesse sentido, estudando os produtores culturais, os artistas ou mediadores culturais, examinando as suas práticas, os seus contextos de inserção, os conteúdos criativos ou modelos ideológicos (MAHON, 200o). Há, também, cada vez mais artistas que, no âmbito dos seus trabalhos, recolhem inspiração na etnografia (MARCUS, 2009).

Por outro lado, as perspectivas da antropologia parecem ser especialmente relevantes para a análise de diferentes dimensões fulcrais para detalhar a condição contemporânea 
das imagens e das linguagens audiovisuais. Destaco apenas duas linhas de pesquisa desenvolvidas no âmbito da antropologia (e de outras ciências sociais), que podem ser particularmente frutíferas para a exploração de alguns dos objectos de investigação mais focados pelos estudos visuais. Desde logo, a grande contribuição da antropologia, para além do seu método particular, parece ser o de colocar no cerne de todo o empreendimento epistemológico o conceito de cultura. Cultura, enquanto conjunto de historicamente fabricado de elementos que tornam reconhecível uma determinada identidade colectiva. Falamos de um conjunto de valores, práticas, representações e artefactos. Neste quadro os bens estéticos são abordados como componentes simbólicos importantes para a comunicação, condensando identidades, representações e valores. Quanto falamos de cultura visual estamos, por isso, a assumir que o visual se encontra enquadrado num certo ambiente cultural que justifica aquilo que é criado, bem como, o seu significado. Todas as imagens construídas pelo homem são, assim, descendentes de um tempo e de um espaço, vectores que permitem identificar um certo ambiente cultural. Um graffiti tem de ser entendido num ambiente cultural urbano, sendo uma expressão estética de jovens vivendo na cidade que absorvem no seu quotidiano uma série de referências imagéticas marcantes na época histórica em que vivem (neste caso a publicidade, o cinema, a televisão, os cartoons, etc.) (CAMPOS, 2010). Por seu turno, os vídeos amadores disponíveis no youtube devem ser percebidos no âmbito de uma cultura altamente tecnológica, onde as consumidores de media são, também, cada vez mais, criadores de conteúdos imagéticos e mediáticos (BURGUESS e GREEN, 2009). O mesmo se princípio se deverá aplicar à arte indígena da amazónia ou à pintura medieval europeia.

A antropologia, aliás como outros ciências sociais, favorece uma abordagem não hierarquizada de cultura, ao contrário daquilo que é prática nos estudos artísticos (história de arte, por exemplo) onde se privilegiam determinados bens estéticos, na medida em que são entendidos como constituindo valores maiores do património cultural duma comunidade. As artes oficiais, social e historicamente legitimadas têm sido, por isso, as áreas de investigação claramente favorecidas. Pelo contrário, a Antropologia interessa-se pelas múltiplas produções simbólicas, a arte de elite, a arte de massas ou a arte popular, não fazendo juízos de natureza estética acerca da qualidade de tais produtos ou processos. A Antropologia tem 
estado, aliás, particularmente atenta às intersecções entre estes campos o que, aliás, está perfeitamente de acordo com estes tempos onde a mobilidade, transformação e hibridismo de linguagens estéticas acontecem com frequência.

Desta constatação decorre uma primeira grande linha de pesquisa, relacionada com aquilo que podíamos intitular como intercâmbios, negociações e hibridismos culturais. Esta dimensão é tanto mais importante quanto constatamos que ao longo de todo o século XX, especialmente na sua segunda metade, se atenuaram uma série de constrangimentos espacio-temporais e o mundo se foi tornando, cada vez mais, interconectado ${ }^{10}$. A globalização (GIDDENS, 1992; WATERS, 1999), para outros a mundialização da cultura (WARNIER, 200o), revela esta preponderância da mobilidade como elemento constitutivo da contemporaneidade. Mobilidade de pessoas, de bens, de imagens e de imaginários. Neste âmbito as referências simbólicas circulam e uma iconografia planetária vai-se, paulatinamente, edificando. As linguagens visuais e audiovisuais, sejam produzidas através dos media electrónicos, sejam produzidas no quadro de outros media e processos comunicativos (imprensa, quadrinhos, cinema, fotografia, pintura, arte de rua, internet, etc.), tendem a incorporar e reformular diferentes referências estéticas e ideológicas, tornando inviável pensar a cultura visual sem a globalização. O graffiti e a street-art são disso um bom exemplo. Originalmente uma linguagem visual circunscrita ao contexto norte-americano da década de 70 do século $\mathrm{XX}$, ao longo de quatro décadas foi-se expandindo planetariamente, tendo sido apropriado em desiguais contextos geográficos e sociais, dando origem, inclusive, a novas linguagens estéticas (aquilo que alguns apelidam de pós-graffiti). Há por isso, quando queremos estudar a cultura visual contemporânea, que estar atentos a esta articulação entre o local e o global, e às metamorfoses de bens e linguagens que dão origem a objectos de índole híbrida.

Outra linha de pesquisa, para a qual a antropologia está particularmente vocacionada, diz respeito à forma como se contemplam os criadores culturais e o processo criativo. Os estudos artísticos, em função do seu objecto de estudo, privilegiam o olhar sobre o artista enquanto indivíduo com particulares qualidades criativas que o colocam, de alguma forma, num patamar de destaque relativamente ao comum dos mortais. Deste modo, a partir de juízos estéticos que balizam a genialidade de pessoas e obras, examinam e 
destacam modelos de superior qualidade. Por seu turno, a Antropologia, mais preocupada em detectar os processos criativos através dos quais o homem em comunidade comunica sentido e representa o mundo, olha para o cidadão comum enquanto criador de significados. Uma etnografia da criação e da recepção estética poderá trazer novos enfoques sobre a experiência estética, mas igualmente sobre os modos como estes circuitos de comunicação artística estão dependentes de posições sociais, de convenções e expectativas que determinam em grande medida a forma como se inventam e consomem as obras. Esta perspectiva é particularmente pertinente se tivermos em conta uma série de transformações sociais, culturais e tecnológicas que conduziram a uma multiplicação do número de criadores de obras de natureza visual e audiovisual. A produção (áudio)visual "privatizou-se enquanto a disseminação se globalizou" diz-nos Muller (2008: 102), o que quer dizer que o cidadão comum tem hoje acesso a um conjunto de instrumentos e dispõe de um leque abrangente de competências, que permitem uma maior produção de bens visuais e vastas possibilidades de disseminação da sua obra. Graffiti, street art, fanzines, vídeos amadores e fotografias caseiras digitais, etc., constituem, hoje em dia, parte deste acervo imagético que é produzido pelo cidadão comum e que compõe uma porção substancial da nossa cultura visual. Há, por isso, que estar mais atento à criatividade simbólica da gente comum e, nomeadamente, daqueles grupos que, geralmente, são menos visíveis ou se encontram nas margens da cultura dominante ou dos sectores mais poderosos da sociedade (os jovens, os imigrantes ou as minorias étnicas, por exemplo) que, por vezes, desenvolvem mecanismos singulares de comunicação e criação cultural. Determinadas linguagens e processos criativos que nascem à margem são, em certas circunstâncias, extremamente influentes, produzindo fortes reverberações nos sectores culturais mais mainstream. O graffiti é um bom exemplo, tendo nascido como manifestação ilegal e marginal, deu origem a uma corrente estética que tem vindo a ganhar peso e reconhecimento por parte das instâncias oficiais e do mundo artístico (galerias, museus, escolas de arte, etc.).

Estas são, no fundo, algumas das linhas de pesquisa e orientações epistemológicas da antropologia que podem, de alguma forma, contribuir para o estudo da cultura visual de certos grupos ou comunidades, para uma análise do papel que as imagens 
e as gramáticas visuais assumem em certos contextos. Diz-nos John Berger (1999:14), que «todas as imagens corporizam um modo de ver». É esse modo de ver e, por conseguinte, de retratar o mundo, que a antropologia pode ajudar a desvendar.

\section{Em jeito de conclusão}

Neste artigo procurei, enquanto antropólogo, equacionar algumas das linhas de intersecção entre a minha disciplina e a área de estudo da cultura visual (ou os estudos visuais). Tendo vindo a trabalhar na área da antropologia visual, tal tarefa não me pareceu complicada, antes pelo contrário, pois tenho defendido as vantagens de tal diálogo. Todavia, quando iniciei esta reflexão cedo me deparei com um primeiro obstáculo. A noção de cultura visual, para além de confusa, é apropriada de forma discrepante pelas diversas áreas de conhecimento. Arquitectura, artes visuais, cinema, psicologia, sociologia, estudos culturais, entre outros, são redutos disciplinares que têm concorrido para uma explicitação deste conceito. Procurei, por isso, defini-lo em função de uma perspectiva essencialmente antropológica. Julgo que esta abordagem poderá ser útil para os Estudos Visuais por diferentes razões. Desde logo, porque viver numa sociedade imersa no visual, onde os objectos e gramáticas visuais se expandiram, onde a produção e disseminação destes bens se alargou, implica estar atento a uma série de processos e transformações sociais e culturais de natureza mais vasta que estão implicados no acto criativo. Ora a Antropologia, para além de partilhar o interesse pelo acto criativo, localizado e subjectivo, estabelece pontes com os contextos circundantes e com horizontes mais vastos que remetem para os processos de mediatização ou globalização, por exemplo. Os artefactos estéticos são engendrados num ambiente cultural e visam preencher um espaço simbólico e comunicacional através do qual as pessoas dão sentido às coisas. Importa, pois, detectar o cultural e o social por detrás das imagens e dos imaginários representados. Compreender a sociedade actual e a sua relação com o olhar e as imagens, obriga a uma grande flexibilidade epistemológica, assente numa abordagem necessariamente interdisciplinar. Neste propósito, o diálogo entre a Antropologia e os Estudos Visuais pode ser extremamente profícuo. 


\section{Referências}

ATKINSON, Paul e HAMMERSLEY, Martyn. Ethnography and participant observation. In DENZIN, Norman e LINCOLN, Yvonna, Strategies of qualitative inquiry, Thousand Oaks, London, New Delhi: Sage Publications, 1998, p.110-136

BRIGHENTI, Andrea. Visibility: a category for the social sciences, Current Sociology,55 (3), p. 323-342, 2007

BERGER, John. Modos de ver. Lisboa: Edições 70, 1999

BURGUESS, Jean e GREEN, Joshua. Youtube: online video and participatory culture, Cambridge: Polity Press, 2009

CAMPOS, Ricardo. Onde é que eu já vi isto?' Imagens e imaginários num mundo familiar". In R. CARMO, D. MELO e R. BLANES (orgs.), A Globalização no Divã, Lisboa: Tinta-da-china, 2008, p. 109-126.

CAMPOS, Ricardo. Das imagens da cultura para a cultura das imagens. In: RIBEIRO José et al, Imagens da Cultura/Culturas das Imagens Actas do IV Seminário Internacional, DVD, Universidade Aberta. 2008

CAMPOS, Ricardo. Porque pintamos a cidade? Uma abordagem etnográfica ao graffiti urbano, Lisboa: Fim de Século, 2010

CLASSEN, Constance. Fundamentos de una antropología de los sentidos, Revista Internacional de Ciencias Sociales, n.으 153, 1997, Disponível em: <www.unesco.org/issj/rics153/ classenspa.html.>, [Consultado em 20 de Maio de 2003]

EDWARDS, Elizabeth. Antropologia e Fotografia. Cadernos de Antropologia e Imagem, no2, p.11-28, 1996

GIDDENS, Anthony. As consequências da modernidade, Oeiras: Celta, 1992

HAMMERSLEY, Martyn e ATKINSON, Paul. Ethnography. Principles in practice, London \& New York, Tavistock Publications. 1983

HANNERZ, Ulf. Fluxos, fronteiras, híbridos: palavras-chave da antropologia transnacional, MANA - Estudos de Antropologia Social, Vol. 3, no 1, 1997,.

JENKS, Chris. The centrality of the eye in western culture: an introduction. In: JENCKS Chris (Ed.) Visual Culture, London and New York: Routledge, 1995. p. 1-25

LIMA DOS SANTOS, Maria de Lourdes. Questionamento à volta de três noções (a grande cultura, a cultura popular e a cultura de massas). Análise Social, nํㅗ 101-102, vol. XXIV, 2o e $3^{\circ}$, p. 689-702, 1988

MACDOUGALL, David. The visual in anthropology. In: BANKS Marcus e MORPHY, Howard (Eds.) Rethinking Vi- 
sual Anthropology. New Haven \& London: Yale University Press, 1997, p. 276-295

MAHON, Maureen The visible evidence of cultural producers, Annual Review of Anthropology, p. 467-492, 2000

MARCUS, George. A estética contemporânea do trabalho de campo na arte e na antropologia: experiências em colaboração e intervenção. In: BARBOSA, Andréa e CUNHA, Edgar e HIJIKI, Rose (orgs.) Imagem-conhecimento. Antropologia, cinema e outros diálogos, São Paulo: Papirus Editora, 2009

MEAD, Margaret. Visual Anthropology in a discipline of words. In HOCKINGS, Paul (Ed.) Principles of Visual Anthropology, Berlin \& New York, Mouton de Gruyter 1995 [1975], p. 3-12

MIRZOEFF, Nicholas An introduction to visual culture, London and New York, Routledge. 1999

MITCHELL, W.J.T. Showing seeing: a critique of visual culture. Journal of Visual Culture, Vol 1(2), p.165-181, 2002

MORPHY, Howard e BANKS, Marcus. Introduction: rethinking visual anthropology. In: BANKS, Marcus e MORPHY, Howard (Ed.) Rethinking Visual Anthropology, New Haven \& London, Yale University Press: 1997, p. 1-35

MULLER, Marion. Visual competence: a new paradigm for studying visuals in the social sciences?. Visual Studies, Vol. 23, nํㅡ, p.101-112, 2008

PIAULT, Marc-Henri. A antropologia e a sua passagem à imagem. Cadernos de Antropologia e Imagem, no1, p. 23-29, p.1995a

PIAULT, Marc-Henri. L'exotisme et le cinema ethnographique: la rupture de la croisière coloniale, Horizontes Antropológicos, Ano 1, № 2, p. 11-18, 1995b

PINNEY, Christopher. História paralela da antropologia e da fotografia, Cadernos de Antropologia e Imagem, №2, p. 2952, 1996

PINNEY, Christopher, Four Types of Visual Culture. In: TILLEY Chris et. al (eds.) Handbook of Material Culture London: Sage. 2006.

ROSE, Gillian. Visual Methodologies - An introduction to the interpretation of visual materials, London, Thousand Oaks, New Delhi: SAGE Publications, 2001

RUBY, Jay. Picturing Culture. Explorations of film E anthropology, Chicago, University of Chicago Press, 2000

RUBY, Jay. The last 20 years visual anthropology. Revista Brasileira de Sociologia da Emoção. V4 nı2, p. 217-218, 2005 
RIBEIRO, José da Silva, Antropologia Visual - Da minúcia do olhar ao olhar distanciado, Porto: Afrontamento, 2004

SAMAIN, Etienne. Ver e dizer na tradição etnográfica: Bronislaw Malinonowski e a fotografia. Horizontes Antropológicos, Ano 1, Número 2, p. 19-48, 1995

SAMAIN, Etienne. No fundo dos olhos: os futuros visuais da antropologia. Cadernos de Antropologia e Imagem, no6, p. 141-158, 1998

SYNNOTT, Anthony. The eye and I: a sociology of sight. Internationl Journal of Politics, Culture and Society, Vol 5, oㅡ 4, p. 617-636, 1992

WALKER, John e CHAPLIN, Sarah. Visual culture: an introduction. Manchester University Press: Manchester e New York. 1997, p. 7 - 30

WARNIER, Jean-Pierre. A mundialização da cultura. Lisboa: Editorial Notícias, 2000

WATERS, Malcolm. Globalização, Oeiras: Celta Editora, 1999

WORTH, Sol. Studying visual communication, Philadelphia: University of Pennsylvania Press, 1981

\section{NOTAS}

1. Nomeadamente a corrente denominada de Antropologia da comunicação visual, especialmente associada a autores como Sol Worth (1981) e Jay Ruby (2000)

2. A ideia da hegemonia da visão é, contudo, como indica Rose (2001), rebatido por autores que, entre outros exemplos, apontam a importância que a imagem assumiu em alguns modelos de espiritualidade medievais e pré-modernos. Também Mitchell (2002) aponta uma série de falácias no discurso comum que conduzem a alguns exageros na forma como se tem determinado a hegemonia da visão e da imagem nos tempos contemporâneos.

3. A pretensão de domínio visual do mundo está presente em inúmeras ferramentas, como o telescópio, o microscópio, o cronofotógrafo, os raios-x, a câmara de fotografar e a de filmar, o aparelho de televisão, as máquinas digitais ou o computador, que são protagonistas relevantes da nossa história.

4. A nossa experiência no mundo é sempre multissensorial. Apesar de geralmente concebidos como utensílios inatos, naturais, universais e transparentes, devemos ter em atenção os modos como são cultural e historicamente modelados. Edward Hall (s.d), nos seus estudos sobre proxémia, revela a importância dos sentidos na forma como construímos a noção de espaço, nos movimentamos nele e comunicamos sentido com os outros seres, revelando que indivíduos pertencendo a culturas distintas, habitam mundos sensoriais e perceptivos diferentes. Classen (1997), por seu turno, fala em diversos modelos sensoriais, considerando diferentes valorizações, hierarquias e utilizações dos sentidos.

5. Particularmente pelos filmes que retratavam a produção do fogo e as danças cerimoniais dos aborígenes.

6. Desenvolveram trabalho de terreno junto de aborígenes australianos utilizando métodos visuais inovadores. 
7. Todavia, esta pulsão pelo (áudio)visual pode ser perigosa, na medida em que o uso não ponderado das tecnologias pode esconder fragilidades metodológicas e teóricas. O uso da imagem precisa, sempre, de ser suportado por uma clara orientação epistemológica que fundamente as razões, processos, objectivos e resultados de tal opção.

8. Os mesmos autores, noutra obra (Hammersley e Atkinson, 1995), definem etnografia como um formato de pesquisa social que abarca os seguintes elementos: forte ênfase na exploração de fenómenos circunscritos; tendência para trabalhar com dados não estruturados (não codificados de acordo com uma grelha de categorias analíticas); escrutínio detalhado de um número limitado de casos; análise de informação que envolve interpretação explícita de significados e funções da acção humana.

9. Geralmente a observação envolve a realização de entrevistas (gravadas e não gravadas, individuais e colectivas), a produção de um diário de campo de acompanhamento do processo e, em muitas circunstâncias, um registo visual (fotografia e vídeo).

10. O enorme desenvolvimento dos transportes e dos media explicam grande parte deste processo.

Recebido em: 02/03/12

Aceito em: 20/03/12 


\section{RICARDO CAMPOS}

rmocampos@yahoo.com.br

Ricardo Campos é Doutorado em Antropologia Visual.. Actualmente é investigador do Laboratório de Antropologia Visual do CEMRI - Centro de Estudos das Migrações e Relações Interculturais, da Universidade Aberta e um dos editores da revista Cadernos de Arte \& Antropologia. É autor do livro Porque pintamos a cidade? Uma abordagem etnográfica ao graffiti urbano (Fim de Século, 2010) e co-organizador do livro Uma cidade de Imagens (Mundos Sociais, 2011). 